\title{
Research and Application of Variable Rate Fertilizer Applicator System Based on a DC Motor
}

\author{
Honglei Jia ${ }^{1}$, Xianzhen Feng ${ }^{1}$, Jiangtao $\mathrm{Qi}^{1{ }^{1}{ }^{*},}$ Xinhui Liu ${ }^{2}$, \\ Chunxi $\mathrm{Liu}^{3}$, Yongxi Yang ${ }^{1}$, and Yang $\mathrm{Li}^{1}$ \\ ${ }^{1}$ Key Laboratory of Bionic Engineering, Ministry of Education, \\ Jilin University, Changchun 130022, China \\ ${ }^{2}$ College of Mechanical Science and Engineering, Jilin University, Changchun 130022, China \\ ${ }^{3}$ Jilin Province Academy of Agricultural Machinery, Changchun 130022, China \\ qijiangtao@jlu.edu.cn
}

\begin{abstract}
With the aim to simplify the electrical component structure of the present variable rate fertilizer applicator system, a kind of variable rate fertilizer applicator control system was developed. It is based on low voltage DC motor. The working voltage of this system is not higher than $12 \mathrm{~V} \mathrm{DC}$, which can be supplied by the tractor's storage battery directly. With the encoder measuring the motor speed, it could response the running state of the motor in real time. A kind of control model based on PID algorithm was built. With this model, the influence of load variation on the motor speed could reduce. As a result, the control accuracy of this system could be improved. Field experiment has been conducted using this system. Experiment showed that when the travel speed was $3.60 \mathrm{~km} / \mathrm{h}$, the maximum fertilizer rate could be $850 \mathrm{~kg} / \mathrm{hm}^{2}$. When the fertilizer rate was $200 \sim 600 \mathrm{~kg} / \mathrm{hm}^{2}$, the mean error of this system was $1.71 \%$ while the maximum error was $2.56 \%$.
\end{abstract}

Keywords: Variable rate technology(VRT), DC motor, PID control.

\section{Introduction}

Variable rate fertilizer technology is a kind of technology that variably input the fertilizer according to the actual need of the crops on the nutrients in the soil[1 4]. The benefit of improving agricultural production and ecological environment has been confirmed [5 7]. In order to master the core techniques in the variable rate fertilizer system, it is meaningful to develop our own variable rate fertilizer applicator system [8].

At present, many domestic research institutions and universities are doing research on the variable rate fertilizer applicator system. In ref.8 and ref.9, two kinds of variable rate fertilizer applicator control system based on CPLD and single-chip microcomputer were designed. The actuators of these systems are stepping motors [8 9]. In ref.10, ref.11 and ref.12, the actuators of the developed system are hydraulic

\footnotetext{
* Corresponding author.
} 
motors[10 12]. The working voltage of the stepping motor and motor driver is higher than $12 \mathrm{~V} \mathrm{DC}$, and it uses alternating current (e.g.110V AC). As for the system with hydraulic motor, the working voltage of electro-hydraulic proportional valve is also higher than $12 \mathrm{~V} \mathrm{DC} \mathrm{[14].} \mathrm{The} \mathrm{storage} \mathrm{battery} \mathrm{voltage} \mathrm{of} \mathrm{the} \mathrm{wheel} \mathrm{tractor} \mathrm{is} 12 \mathrm{~V} \mathrm{DC}$, in order to meet the requirements of the present system, inverter and transformer are needed. Thus, the electrical component structure of the system becomes complicated and the volume becomes huge, which also increases the cost.

In order to increase the system's control accuracy and simplify the electrical component structure, a kind of PID control system is developed in this paper. In this system, the DC motor is used as the actuator and an encoder is used to measure the motor speed. Besides, the working voltage of this system is not higher than $12 \mathrm{~V} \mathrm{DC}$.

\section{Experiments and Methods}

\subsection{The Composition of the Whole System}

The composition of this system is shown in figure 1 .

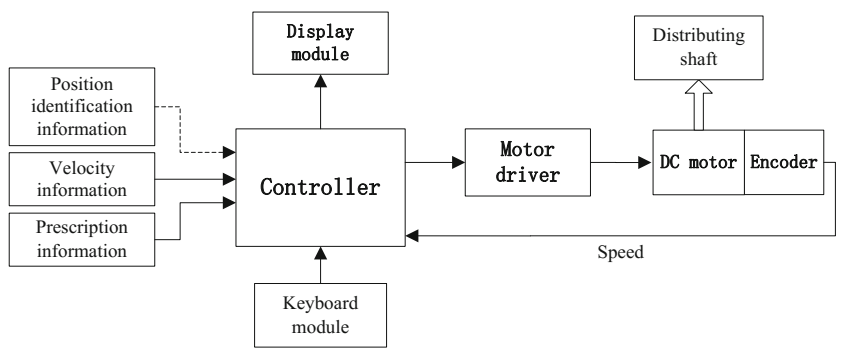

Fig. 1. Block diagram of the whole system

There are two kinds of working mode in this system: automatic mode and manual mode. In the automatic mode, the controller gains the position identification information, reads the corresponding grid prescription information stored in advance and gains the speed information from the speed sensor. With this information, the controller makes fertilization decision and generates pulse or analog voltage driving signal. The fertilization decision is made according to the fertilization decisionmaking formula, and the driving signal is transferred to the motor driver. The motor driver drives the DC motor to run. The encoder which is coaxially connected with the motor runs with the motor. At the same time, the controller gains the output information of the encoder and controls the motor running at a certain speed by applying the PID algorithm. Then the shaft of the fertilizer rotates driven by the DC motor through the chain. In the manual mode, the working process is the same as automatic mode except that the fertilizer rate information is manually inputted, not from the advanced stored grid prescription.

The grid position identification information can be acquired from the GPS devices [8 12] or by using the positioning technology based on speed sensor [14]. The Dead 
Reckoning (DR) positioning method based on speed sensor is used as the positioning method in this system.

\subsection{The Design of System Hardware}

According to the function requirements of the system, the system mainly include: the single-chip microcomputer as the core controller, the speed acquisition module that gathers speed information, the keyboard module that used for inputting information, the display module that used for displaying the working state information of the machine, the motor driving module that used for driving the DC motor, the encoder used for gaining feedback of motor speed and the data recording module used for recording the working state of the fertilizer applicator.

\subsubsection{The Selection of Motor Driver}

Motor driver receives control signal from the controller, and outputs driving current to drive the motor. Its performance has direct influence on the stability and accuracy of the system. This system selects the motor driver produced by Beijing YongGuang gaote micro motor Co., LTD, the product model is YG8008-8EI. The driver has two kinds of control methods: pulse signal (+5V DC square-wave pulse) and analog voltage signal $(-10 \mathrm{~V}$ DC $\sim+10 \mathrm{~V}$ DC). The working voltage is between $+12 \mathrm{~V}$ DC $+36 \mathrm{~V}$ DC, which can be supplied by the tractor's storage battery directly.

\subsubsection{The Selection of Controller}

The controller has the following functions:(1) Generating pulse and analog driving signal. The signal is transferred to the motor driver to control the motor (2) Receiving the conditioned speed sensor signal, used for computing the machinery speed and calculating the grid information (3) Receiving the input information from the keyboard module (4) Controlling the LCD display module to display the working state information of the machine (5)Receiving the output of the encoder to measure the actual motor speed.

In order to meet the functions described above, the controller should have fast processing speed and rich timer/counter resources. This system selected a kind of $1 \mathrm{~T}$ single-chip microcomputer, the product model is STC12C5A60S2. It has two programmable counter array (PCA) modules, which can be used to extend the timer resources to meet requirements of the system. At the same time, it is a kind of $1 \mathrm{~T}$ controller. The processing speed can meet the system's requirement.

\subsubsection{The Selection and Configuration of DC Motor and Encoder}

The universal tillage machine 1GT-6 developed by College of Biological and Agricultural Engineering of Jilin University was used as the test prototype in this study. The rotational resistance of the shaft of the prototype was tested by using torque tester, the torque range is $2 \mathrm{~N} \bullet \mathrm{m} \sim 4 \mathrm{~N} \bullet \mathrm{m}$. Considering the complexity of the operation environment of the agricultural machinery, taking great safety margin, the torque of the required motor should be more than $10 \mathrm{~N} \bullet \mathrm{m}$. A kind of rare earth 
permanent magnet (REPM) DC motor produced by Beijing YongGuang gaote micro motor Co., LTD was used in this system, the product model is 130LYX-05F. Its maximum torque is $11 \mathrm{~N} \cdot \mathrm{m}$, and its maximum speed is $300 \mathrm{r} / \mathrm{min}$. According to the test, when the working voltage is $12 \mathrm{~V} \mathrm{DC}$, the speed can be $100 \mathrm{r} / \mathrm{min}$. If the travel speed is $3.60 \mathrm{~km} / \mathrm{h}$, the fertilizer rate can reach $850 \mathrm{~kg} / \mathrm{hm} 2$, which meeting the requirements of this study.

The model of incremental encoder used by this system is PHB8-3600-G05L. It outputs 3600 pulse per revolution and its working voltage is 5V DC. The encoder and the motor are coaxially connected by the encoder support. The encoder support is made of metal piece. As the encoder support is a bit flexible, the concentricity between the encoder and the DC motor can be ensured. The specific mechanism is shown in figure 2:
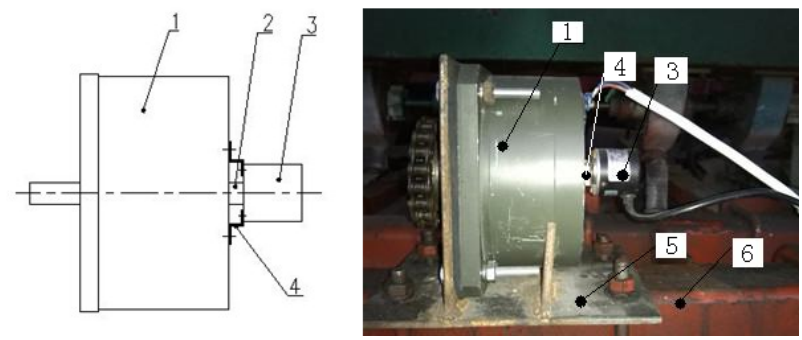

Fig. 2. Arrangement and setting of the DC motor and the encoder

1. Motor 2.Motor shaft 3.Encoder 4.Encoder support 5. Motor base 6. Machine beam

\subsubsection{The Generation of the Analog Driving Voltage}

The motor driver has two driving modes: pulse signal and analog voltage signal. The pulse driving mode is the prime selection, because the pulse signal can be generated by the controller directly. It is accurate and can also simplify the design of the system hardware. In order to guarantee the reliability of the prototype system, in this study, the analog driving circuit has also been designed. If something is wrong with the pulse driving mode, the operator can switch to analog signal driving mode quickly.

The principle diagram that produces analog driving voltage signal is shown in figure 3 .

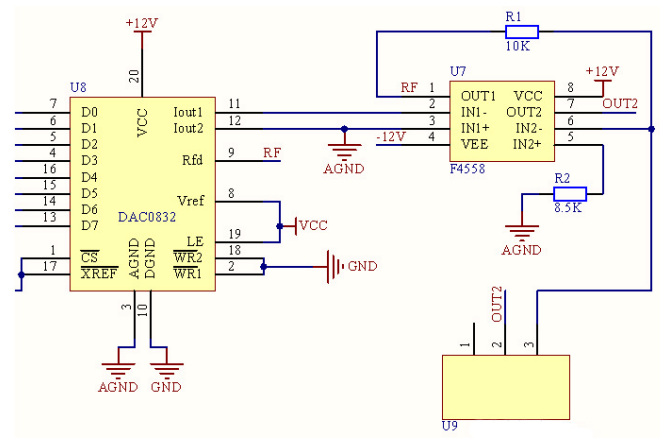

Fig. 3. Schematic of analog driving signal 
The data bus D0-D7 of the D/A conversion chip DAC0832 is connected with the P0 port of the single-chip microcomputer. The data of D0-D7 controls the current of Iout1 and Iout2. F4558 is a kind of double operational amplifier chip, it converts Iout1 and Iout2 into the driving voltage signal. However, F4558 needs a negative power (-12V DC) supply. It would certainly increase the complexity of the hardware if voltage conversion chip is used. According to the datasheet of LCD module JM160128B, the 20th pin (VEE) of JM160128B can output $-13.7 \mathrm{~V}$ DC used to adjust the contrast of the LCD. The F4558 chip can use part of the voltage of this pin as the $12 \mathrm{~V}$ DC power supply. In this way, we solve the power supply problem without increasing the cost of the hardware.

\subsubsection{The Design of Speed Acquisition Module}

Speed is one of the most critical factors for the variable rate fertilizer applicator system. The Hall sensor was used as the speed sensor in the speed acquisition module. Magnet slices installed on wheel hub of the rear wheel of the tractor, a total of 16 slices were used. The specific installation form is shown in figure 4.

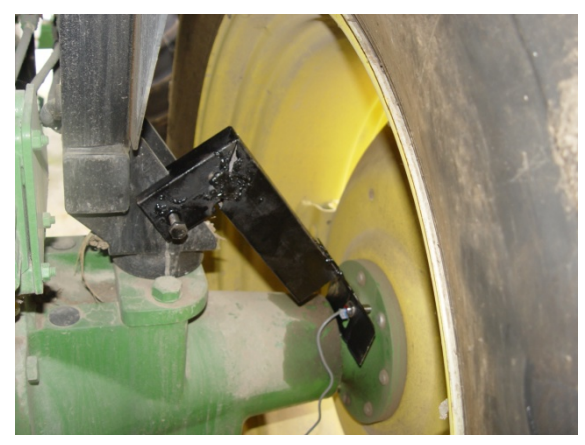

Fig. 4. Setting of speed sensor

\subsubsection{The Design of Human-computer Interaction Module}

In this system, grid number, fertilizer rate, travel speed, theory speed of the shaft of the fertilizer, and actual speed of the shaft of the fertilizer are the information needed to be displayed. The LCD module, whose product model is JM160128B, was used as the display module in this system.

The system selected $4 \times 4$ matrix keyboard to input information. There are 10 number buttons (0 9), 4 direction buttons (up, down, left and right), the "Confirm" button and the "Back" button.

\subsection{The Design of System Software}

The main function of the system software is counting the speed pulse, scanning and identifying the matrix keyboard, calculating pulse signal frequency used to control the motor, providing driving code for the LCD and recording the working state of the fertilizer applicator. 


\subsubsection{The Relationship between the Speed and Speed Pulse}

The speed expression of the fertilizer is

$$
v=\frac{C}{N_{1}} \times \pi \times D \times 3.6
$$

$\mathrm{v}$ - Travel speed, $\mathrm{km} / \mathrm{h}$

$\mathrm{C} \_$Pulse number per unit time, number/min

N1 _ Number of magnet slice, number

$\mathrm{D} \longrightarrow$ Diameter of tractor rear wheel, $\mathrm{m}, \mathrm{D}=0.57 \mathrm{~m}$

The fertilizer sowing amount of the feed is

$$
q=\frac{10}{6} v B Q \times 10^{-3}
$$

$\mathrm{q}-$ Fertilizer sowing amount of every feed per minute, $\mathrm{kg} / \mathrm{min}$

$\mathrm{B}-$ Row space of the fertilizer applicator, $\mathrm{m}, \mathrm{B}=0.65 \mathrm{~m}$

$\mathrm{Q}$ _-Fertilizer rate per hectare, $\mathrm{kg} / \mathrm{hm} 2$

The relationship between $q$ and distributing shaft speed $n$ is [15]

$$
q=k n+b
$$

$\mathrm{n}$-Distributing shaft speed, $\mathrm{r} / \mathrm{min}$

$\mathrm{k}-$ Coefficient constant

$\mathrm{b}-$ Coefficient constant

According to (2) and (3), the relationship between $\mathrm{Q}$ and $\mathrm{n}$ is

$$
\mathrm{n}=\left(\frac{10}{6} \mathrm{vBQ} \times 10^{-3}-b\right) / k
$$

\subsubsection{The PID Algorithm to Control the Motor Speed}

The PID control is a widely used control method in the control system [16]. It has the advantages of simple structure and good stability. Parameter setting is convenient and robust. In order to enhance the stability of the variable rate fertilizer applicator system and reduce the control error, the control model was established based on the PID algorithm as shown in figure 5, the differential expression of the mathematical model $[17]$ is

$$
V o(t)=K_{p} \cdot e(t)+K_{i} \cdot \int_{0}^{t} e(t) d t+K_{d} \cdot \frac{d e(t)}{d t}
$$

$\mathrm{e}(\mathrm{t})=\mathrm{VO}(\mathrm{t})-\mathrm{Vi}(\mathrm{t})$

$\mathrm{K}_{\mathrm{p}} \longrightarrow$ Proportional coefficient

$\mathrm{K}_{\mathrm{d}} \longrightarrow$ Differential coefficient

$\mathrm{K}_{\mathrm{i}}$ - Integral coefficient 
The transfer function is

$$
\mathrm{G}(\mathrm{s})=\frac{V o(s)}{V i(s)}=K_{p}+K_{d} s+\frac{K i}{s}
$$

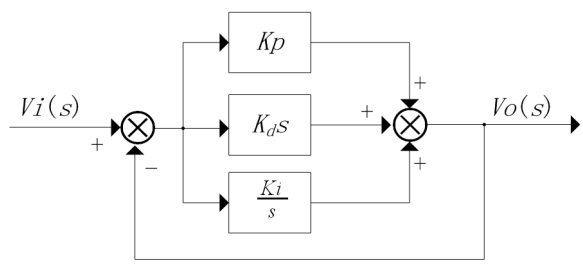

Fig. 5. Control mode of PID controller

\subsection{Flowchart of System Software}

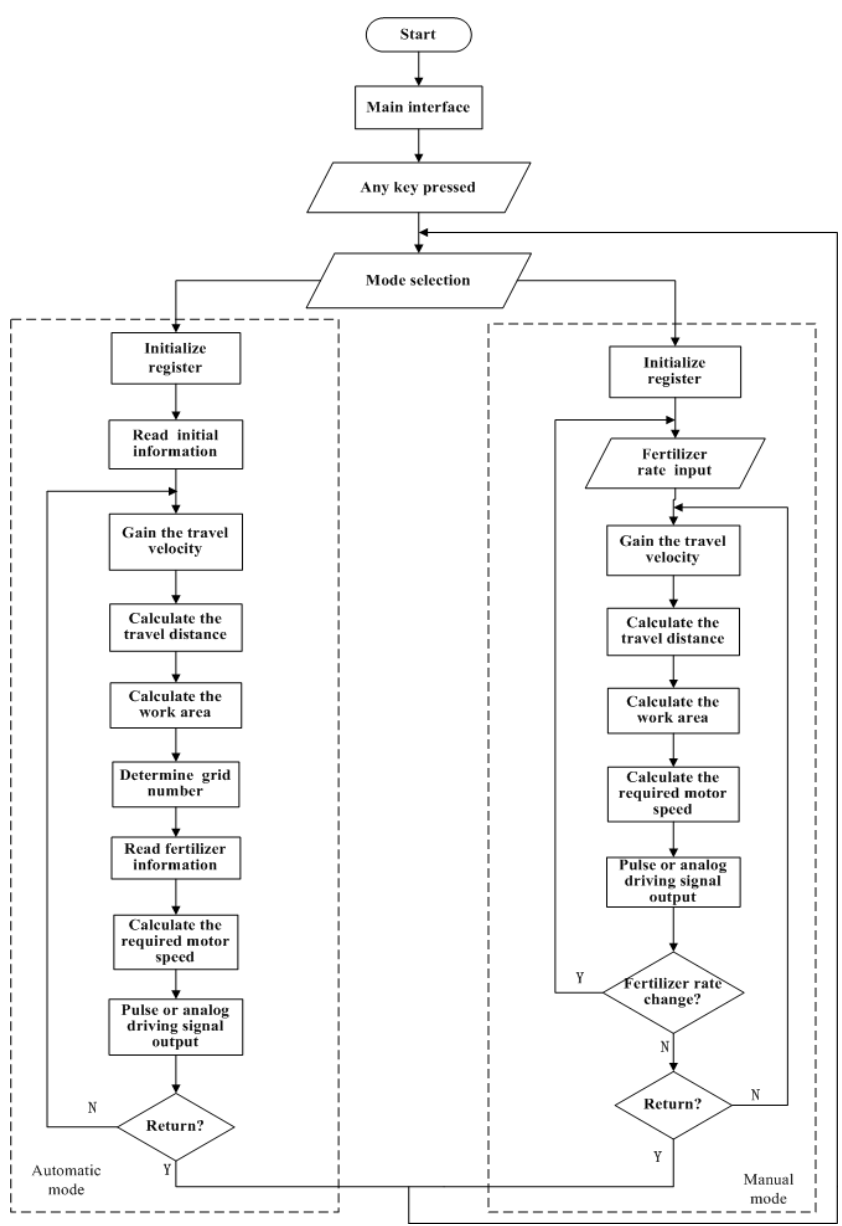

Fig. 6. Flowchart of the system procedures 
The main interface will appear once the system is turned on. In the main interface, the system information and welcome message is displayed in this window. Only if the user presses one of the keys, the system will turn to the work mode selection interface. Then the software turn to "automatic mode" or "manual mode" according to the user's selection. The specific flowchart of the system software is shown in figure 6.

\section{$3 \quad$ System Calibration and Test Result Analysis}

In order to determine the constant coefficient $\mathrm{k}$ and $\mathrm{b}$, calibration experiment should be carried out before the system starts to work[18]. The experiment used external force fertilizer, granular urea. The environment temperature is $10{ }^{\circ} \mathrm{C}$. First of all, measuring the consistency of the fertilizer at the speed of $n=45 \mathrm{r} / \mathrm{min}$, and adjusting the feed to meet the consistency requirement. Then measuring the displacement of every feed at the speed between $10 \mathrm{r} / \mathrm{min}$ and $80 \mathrm{r} / \mathrm{min}$ in turn.

Table 1. Displacement of fertilizer feed in diffident shaft speed

\begin{tabular}{|c|c|c|c|c|c|c|c|c|c|}
\hline $\begin{array}{l}\text { Time } \\
\text { t/s }\end{array}$ & $\begin{array}{l}\text { Shaft } \\
\text { speed } \\
\text { n /r·min }\end{array}$ & $\begin{array}{l}\text { Feed } \\
\text { NO.1 } \\
\mathrm{m}_{1} / \mathrm{kg} \\
\end{array}$ & $\begin{array}{l}\text { Feed } \\
\text { NO.2 } \\
\mathrm{m}_{2} / \mathrm{kg} \\
\end{array}$ & $\begin{array}{l}\text { Feed } \\
\text { NO.3 } \\
\text { m }_{3} / \mathbf{k g} \\
\end{array}$ & $\begin{array}{l}\text { Feed } \\
\text { NO.4 } \\
\mathrm{m}_{4} / \mathrm{kg} \\
\end{array}$ & $\begin{array}{l}\text { Feed } \\
\text { NO.5 } \\
\mathrm{m}_{5} / \mathrm{kg} \\
\end{array}$ & $\begin{array}{l}\text { Feed } \\
\text { NO.6 } \\
\mathrm{m}_{6} / \mathbf{k g} \\
\end{array}$ & $\begin{array}{l}\text { Total } \\
\Sigma / \mathbf{k g}\end{array}$ & $\begin{array}{l}\text { Mean } \\
q / \mathrm{kg}\end{array}$ \\
\hline 60 & 10 & 0.41 & 0.44 & 0.42 & 0.39 & 0.42 & 0.41 & 2.48 & 0.41 \\
\hline 60 & 20 & 0.82 & 0.85 & 0.84 & 0.80 & 0.90 & 0.84 & 5.04 & 0.84 \\
\hline 60 & 30 & 1.22 & 1.25 & 1.26 & 1.18 & 1.27 & 1.22 & 7.40 & 1.23 \\
\hline 60 & 40 & 1.48 & 1.50 & 1.49 & 1.46 & 1.52 & 1.48 & 8.94 & 1.49 \\
\hline 60 & 50 & 2.00 & 2.05 & 2.04 & 1.90 & 2.03 & 1.97 & 11.99 & 2.00 \\
\hline 60 & 60 & 2.12 & 2.15 & 2.15 & 2.10 & 2.11 & 2.13 & 12.78 & 2.13 \\
\hline 60 & 70 & 2.10 & 2.31 & 2.40 & 2.31 & 2.34 & 2.37 & 13.83 & 2.31 \\
\hline 60 & 80 & 2.76 & 2.75 & 2.80 & 2.75 & 2.81 & 2.74 & 16.68 & 2.78 \\
\hline
\end{tabular}

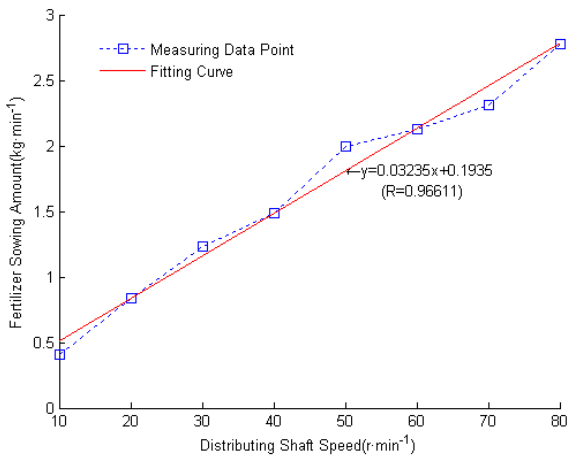

Fig. 7. Fitting curves between displacement of fertilizer feed and shaft speed 
The linear fitting between $\mathrm{q}$ and $\mathrm{n}$ according to the experiment result is

$$
q=0.03235 n+0.1935
$$

Namely, $k=0.03235, b=0.1935$, with the equation (4), the final fertilization decisionmaking formula is

$$
\mathrm{n}=\left(\frac{10}{6} \times 0.65 \mathrm{vQ} \times 10^{-3}-0.1935\right) / 0.03235
$$

In order to validate the performance of the system, in the autumn of 2012, field test was conducted in the test field of Changchun Academy of Agricultural Sciences, as shown in figure 8.

In order to test the fertilizer distributing performance of the prototype, the machine runs 20 meters at the speed of $3.60 \mathrm{~km} / \mathrm{h}$. The falling fertilizer was collected with plastic bags. In theory, the fertilizer sowing amount $\mathrm{M}$ is

$$
\frac{M}{N_{2} \times B \times 20}=\frac{Q}{10000}
$$

$\mathrm{N}_{2}-$ number of fertilizer pipe, $\mathrm{N}_{2}=4$

$\mathrm{M} —$ theory fertilizer sowing amount, $\mathrm{kg}$

Namely

$$
M=5.2 \times 10^{-3} Q
$$

Table 2. Prototype test of distributing performance

\begin{tabular}{llll}
\hline $\begin{array}{l}\text { Fertilizer } \\
\text { rate }\end{array}$ & $\begin{array}{l}\text { Theory sowing } \\
\text { amount } \\
\mathbf{Q} / \mathbf{k g}\end{array}$ & $\begin{array}{l}\text { Actual sowing } \\
\mathbf{M} / \mathbf{k g}\end{array}$ & $\begin{array}{l}\text { Relative error } \\
\boldsymbol{M}^{\prime} / \mathbf{k g}\end{array}$ \\
\hline 200 & 1.04 & 1.05 & $\boldsymbol{\mu} / \%$ \\
300 & 1.56 & 1.58 & 0.96 \\
400 & 2.08 & 2.05 & 1.28 \\
500 & 2.60 & 2.54 & 1.44 \\
600 & 3.12 & 3.04 & 2.31 \\
\hline Ave & & & 2.56 \\
Max & & & 1.71 \\
\hline
\end{tabular}

The field experiment shows that the maximum fertilizer rate can be $850 \mathrm{~kg} / \mathrm{hm} 2$, when the travel speed is $3.60 \mathrm{~km} / \mathrm{h}$. When the fertilizer rate is $200 \sim 600 \mathrm{~kg} / \mathrm{hm} 2$, the mean error of this system is $1.71 \%$, the maximum error is $2.56 \%$. Its stable and reliable performance prove that it's a kind of feasible method for variable rate fertilizer applicator. 


\section{Conclusions}

(1)With large torque DC motor as the actuator of variable rate fertilizer applicator system, the working voltage of the whole system is not higher than $12 \mathrm{~V} \mathrm{DC}$, which can be supplied by the tractor's storage battery directly. The electrical component structure of the variable rate fertilizer applicator was greatly simplified.

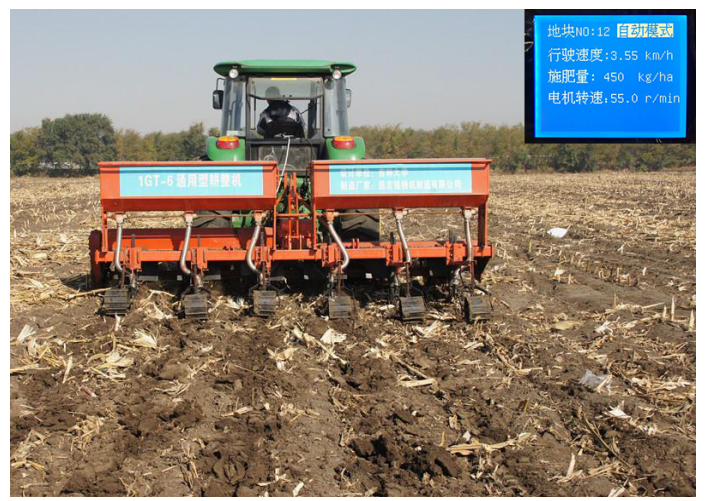

Fig. 8. Field experiment

(2)With the incremental encoder being the motor speed detection device, the controller can monitor the motor speed in real-time. Establishing a control mode with the PID algorithm improves the control accuracy of the system.

(3)Applying this system to the field operation, it works stably. The maximum fertilizer rate can be $850 \mathrm{~kg} / \mathrm{hm} 2$ when the travel speed is $3.60 \mathrm{~km} / \mathrm{h}$. When the fertilizer rate is $200 \sim 600 \mathrm{~kg} / \mathrm{hm} 2$, the mean error of this system is $1.71 \%$, while the maximum error is $2.56 \%$.

Acknowledgment. This study was supported by the Key Projects in the National Science \& Technology Pillar Program of China during the 12th Five-Year Plan period (2011BAD20B09) and Scientific and Technological Development Projects in Jilin Province (No. 20125026).

\section{References}

1. Yang, C., Everitt, J.H., Bradford, J.M.: Comparisons of uniform and variable rate nitrogen and phosphorus fertilizer applications for grain sorghum. Transactions of the American Society of Agricultural Engineers 44(2), 201-209 (2001)

2. Zhang, S., Ma, C., Li, W., Xui, Y.: Experimental study on the influence of variable rate fertilization on maize yield and soil nutrients. Transactions of the Chinese Society of Agricultural Engineering 22(8), 64-67 (2006)

3. Wittry, D.J., Mallarino, A.P.: Comparison of uniform-and variable-rate phosphorus fertilization for corn-soybean rotations. Agronomy Journal 96(1), 26-33 (2004) 
4. Saeys, W., Deblander, J., Ramon, H., Anthonis, J.: High-performance flow control for sitespecific application of liquid manure. Biosystems Engineering 99(1), 22-34 (2008)

5. Zhijun, M., Chunjiang, Z., Hui, L., Wenqian, H., Weiqiang, F., Xiu, W.: Development and performance assessment of map-based variable rate granular application system. Journal of Jiangsu University: Natural Science Edition 30(4), 338-342 (2009)

6. Meng, Z., Zhao, C., Fu, W., Ji, Y., Wu, G.: Development and performance assessment of map-based variable rate granular application system. Journal of Jiangsu University: Natural Science Edition 30(4), 204-209 (2009)

7. Chengyu, Z., Haifeng, X.: Our country measuring soil fertilizer technology to increase revenue and reduce expenditure effect research_— Based on empirical analysis of jiangsu and jilin provinces. Agricultural Technical and Economic (2), 44-51 (2009)

8. Zhang, S., Qi, J., Liao, Z., Xu, Y.: Research and application of control system for variable rate fertilizer applicator based On CPLD. Transactions of the the Chinese Society of Agricultural Engineering 26(8), 200-204 (2010)

9. Xu, M., Chenglin, M., Guoqi, S., Jiang, Z.: Design of variable rate fertilizer applicator. Transactions of the Chinese Society for Agricultural Machinery 36(1), 50-53 (2005)

10. Xiu, W., Chunjiang, Z., Zhijun, M., Liping, C., Yuchun, P., Xuzhang, X.: Design and experiment of variable rate fertilizer applicator. Transactions of the Chinese Society of Agricultural Engineering 20(5), 114-117 (2004)

11. Chunying, L., Xi, W., Jun, Z., Zhimin, W., Weidong, Z.: Design of the velocity system of the valve-controlled motor on the variable rate fertilizer applicator. Journal of Hei Long Jiang August First Land Relamation University 15(3), 47-50 (2003)

12. Baofu, H., Chunying, L., Xi, W., Aiping, L., Hongxia, Z.: Design of control system of variable rate fertilization. Journal of Heilongjiang Bayi Agricultural University 23(4), 68$71(2011)$

13. Linhuan, Z.: Study on hydraulic stepless speed control system of the variable rate fertilizer applicator. JiLin University, JiLin (2009)

14. Yu, Y., Zhang, S., Qi, J., Xu, Y., Wang, W.: Positioning Method of Variable Rate Applicators in Irregular Field. Transactions of the Chinese Society for Agricultural Machinery 42(2), 158-161 (2011)

15. Zhang, S., Ma, C., Du, Q., Nie, X., Wu, C., Han, Y.: Design of control system of variable rate fertilizer applicator in precision agriculture. Transactions of the Chinese Society of Agricultural Engineering 20(1), 113-116 (2004)

16. Yonghua, T.: New type of PID control and application. Machinery Industry Press, Beijing

17. Liang, C., Yi, S., Xi, W., Huai, B.F.: PID Control Strategy of the Variable Rate Fertilization Control System. Transactions of the Chinese Society for Agricultural Machinery 41(7), 157-162 (2010)

18. Wei, L., Zhang, X., Yuan, Y., Liu, Y., Li, Z.: Design and experiment of 2F-6-BP1 variable rate assorted fertilizer applicator. Transactions of the Chinese Society of Agricultural Engineering 28(4), 14-18 (2012) 